\title{
PROGRAM AUTHORITATIVE PARENTING UNTUK MEREDUKSI PERILAKU DISTRUPTIF PADA ANAK
}

\author{
Tuti Alawiyah Rahman ${ }^{1}$, Devy Sekar Ayu Ningrum ${ }^{2}$ \\ 1) Program Studi Bimbingan dan Konseling, IKIP Siliwangi, tutialawiyah@ikipsiliwangi.ac.id \\ 2) Program Studi Bimbingan dan Konseling, IKIP Siliwangi, devysekar@ikipsiliwangi.ac.id
}

\begin{abstract}
Abstrak
Artikel ini bertujuan untuk mendeskripsikan implementasi program authoritative parenting kepada orang tua di SD X kota Cimahi. Pelaksanaan program authoritatif parenting dalam rentang waktu September 2020 s/d Oktober 2020. Kegiatan program ini terdiri dari tiga tahap, yaitu tahap perencanaan, pelaksanaan dan evaluasi. Tahap pelaksanaan dengan menggunakan teknik ceramah, diskusi, dan pendampingan serta tahap evaluasi. Berdasarkan hasil angket respon orang tua yang diberikan sebelum dan setelah diberikan program authoritative parenting menunjukkan adanya peningkatan pemahaman dan penggunaan authoritative parenting sebesar 57,3\%. Sedangkan pada angket respon orang tua sebelum dan setelah diberikan materi mengenai perilaku distruptif pada anak menunjukkan adanya penurunan atau mereduksi perilaku distruptif pada anak sebesar 30\%. Hal ini dapat disimpulkan bahwa kegiatan pengabdian ini cukup baik dan efektif.
\end{abstract}

Kata Kunci : anak, authoritative Parenting, orangtua, perilaku distruptif

\begin{abstract}
This article aims to describe the implementation of authoritative parenting training for parents at SD X of Cimahi. The authoritative parenting training held from September to October 2020. This training activity consists of three stages, namely the planning, implementation and evaluation stage. The implementation stage using lecture, discussion, and mentoring techniques. Based on questionnaire result on authoritative parenting given to parent before and after the training, it showed an increase in understanding and use of authoritative parenting by $57.3 \%$. Whereas in the parents' responses questionnaire on distracting behavior in children, it shows that there is a decrease or reduce distracting behavior in children by $30 \%$. It can be concluded that authoritative parenting training given to parent is quite good and effective in reducing children disruptive behaviour.
\end{abstract}

Keywords: Authoritative Parenting, children, disruptive behavior, parents

\section{PENDAHULUAN}

Orang tua memiliki tugas dan tanggungjawab yang besar dalam pengasuhan dan pendidikan anak yang sering kita sebut sebagai parenting. Dibutuhkan pendidikan keterampilan pengasuhan anak agar orang tua (ibu) agar siap menjadi seorang ibu dan memberikan pengasuhan kepada anak-anak. Pada kenyataannya di masyarakat program untuk parenting ini masih sangat sedikit dilakukan. Minimnya pelatihan membuat orang tua menjadi kurang dapat memahami apa yang dibutuhkan oleh anak. Orang tua menjadi kurang memperhatikan perkembangan dan masalah-masalah yang dihadapi anak-anak. Pola asuh (Diana Baumrind, 1967), pada prinsipnya merupakan parental control yaitu bagaimana orangtua mengontrol, membimbing, dan mendampingi anak-anaknya untuk melaksanakan tugas-tugas perkembangannya menuju pada proses pendewasaan. Tugas-tugas perkembangan yang harus dilalui oleh anak membutuhkan stimulasi dan pengarahan serta bimbingan dari orang tua. Terkadang dalam pelaksanannya anak-anak menunjukkan perilaku distruptif atau perilaku yang mengganggu orang lain. Perilaku distruptif ini juga banyak terjadi pada anak-anak. Kondisi ini akan menjadi semakin parah ketika orangtua memberikan pengasuhan yang salah kepada anak. 
Terdapat tiga pola pengasuhan menurut Diana Baumrind (1967) yaitu Authoritarian Parenting (Pola asuh otoriter), Authotitative Parenting (Pola asuh demokratis/otoritatif) dan Permissive Parenting (Pola asuh permisif). Authoritatif parenting ini dapat membuat anak menjadi mandiri, memiliki kontrol diri yang baik dan memiliki keterampilan sosial yang baik. dalam hal ini perilaku distruptif yang anak tunjukkan dapat diatasi dengan menggunakan Authoritatif parenting. Perilaku disruptif (DSM V) merupakan pola perilaku melanggar hak orang lain, agresi, perusakan properti dan perilaku yang membawa individu mengalami konflik yang signifikan dengan pelanggaran norma sosial atau figur otoritas.

Berdasarkan data yang didapatkan oleh tim pengabdian masyarakat Prodi Bimbingan dan Konseling IKIP Siliwangi bahwa banyak sekali orang tua siswa yang membutuhkan program pelatihan authoritative parenting dalam mengatasi masalah-masalah perilaku distruptif pada anak. Orang tua membutuhkan pembekalan yang memadai mengenai parenting agar dapat menjadi orang tua yang baik dalam mengatasi perilaku distruptif anak. Orang tua kurang mendapatkan kesempatan yang memadai untuk dapat belajar mengasuh dan mendidik anak dengan cara yang tepat. Hal ini juga dikatakan oleh kepala sekolah SD X Kota Cimahi bahwa banyaknya anak yang menunjukkan perilaku distruptif di sekolah disebabkan karena pola pengasuhan yang keliru dari orangtuanya. Orang tua juga merasa khawatir dengan minimnya pengetahuan mereka mengenai parenting dapat membuat anak dapat terpengaruh dengan perilaku negatif dari lingkungan dan pada akhirnya anak-anak banyak yang menunjukkan perilaku distruptif baik di sekolah maupun di rumah.

Berdasarkan kondisi yang dapatkan di lapangan, tim pengabdian Program Studi Bimbingan dan Konseling bermaksud untuk memberikan program pelatihan authoritative parenting untuk mereduksi perilaku distruptif pada anak.

\section{Konsep Authoritative Parenting}

Authoritative Parenting atau pengasuhan otoritatif merupakan pola asuh orang tua terhadap anaknya yang bersifat demokratis dimana orang tua menciptakan lingkungan pengasuhan yang mendukung dan responsif namun tetap dengan batasan yang tegas. Konsep ini pertama kali diperkenalkan oleh Diane Baumrind (1966) dengan mengemukakan tiga pola pengasuhan orang tua, yaitu; 1) Permissive parenting, adalah pola asuh dimana orang tua yang enggan menegakan aturan dan standar-standar tertentu serta cenderung membiarkan anak mereka berperilaku sesuai dengan keinginannya; 2) Authoritarian parenting, adalah pola asuh dimana orang tua cenderung menggunakan pendekatan otoriter dan menuntut anak untuk mengikuti aturan- aturan atau standar-standar yang dibuat oleh orang tua; 3) Authoritative parenting, merupakan pola asuh yang lebih moderat dimana orang tua menekankan pada pengasuhan dan lebih responsif terhadap anak mereka, serta menunjukan sikap menghargai terhadap indenpendensi dan pikiran rasional anak. Pola asuh otoritatif ini dimaksudkan agar anak dapat lebih matang dan bekerja sama dan memberikan banyak emotional support kepada anak-anak.

Sama seperti permissive parenting, authoritative parenting bersifat responsif, mengasuh dan terlibat, namun yang membedakannya adalah orang tua dengan pola asuh otoritatif tidak membiarkan perilaku buruk anaknya. Orang tua memberi batasan yang tegas terhadap perilaku anak mereka serta mendorong anak mereka untuk bertanggung jawab terhadap perilaku mereka.

Apabila dibandingkan dengan pola asuh authoritarian dimana orang tua mengendalikan perilaku anak mereka dengan paksaan dan ancaman, pola asuh otoritatif cenderung mengajak anak bekerja sama dan menanamkan perasaan positif serta mengajarkan anak alasan dibalik peraturan-peraturan yang harus mereka ikuti.

Orang tua otoritatif banyak melakukan komunikasi yang hangat dengan anaknya, mereka cenderung menghindari kata-kata kasar dan hukuman. Ketika anak berbuat salah, orang tua mendiskusikan kesalahan tersebut dengan anak mereka, penjelasan anak didengar dan anak diberikan pemahaman tentang kesalahan dalam perilaku mereka.

Berdasarkan beberapa penelitian yang telah dilakukan, dapat disimpulkan bahwa pola asuh otoritatif cenderung memberikan tuntutan kepada anak seperti halnya pola asuh authoritarian namun 
pada saat yang bersamaan orang tua sangat resposif terhadap kebutuhan anak mereka (Maccoby and Martin 1983).

\section{Perilaku Disruptif}

Perilaku disruptif merujuk pada gangguan perilaku yang dialami anak-anak terutama pada anak usia dini, Gardner dan Shaw (2008). Gangguan perilaku ini berpotensi mengganggu orang lain apabila tidak dideteksi sejak dini (Campbell, 2006). Gangguan perilaku ini dapat berupa pelanggaran aturan, agresivitas atau hiperaktivitas yang cenderung berulang dan mengganggu orang disekitarnya.

Secara lebih spesifik, Schroeder \& Gordon (2002) mendefinisikan perilaku disruptif sebagai serangkaian perilaku yang tidak sesuai (inappropriate) seperti temper tantrum, merengek atau menangis berlebihan, menuntut perhatian, tidak patuh, menantang, tindakan agresif yang membahayakan diri sendiri atau orang lain, pencurian, berbohong, pengrusakan barang, dan delikuensi.

Sementara, Crozeir \& Tincani (2005) dalam Asizah (2015) menggambarkan disruptive behavior dengan menggunakan istilah externalizing behavior yaitu masalah perilaku yang ditujukan pada orang lain atau dunia luar. Rentang disruptive behavior mulai dari pelanggaran ringan seperti melawan dengan kata-kata sampai tindakan agresi yang parah.

Perilaku disruptif perlu dideteksi sejak dini, karena kalau tidak ditangani dengan benar, maka perilaku tersebut akan semakin menguat seiring dengan bertambahnya usia. Sebagaimana hasil penelitian yang dilakukan oleh Tillman, dan Luby (2015) yang menunjukan bahwa anak yang mempunyai sikap disruptif perilakunya cenderung menguat seiring dengan bertambahnya usia dan ada kemungkinan mengalami conduct disorder.

Perilaku disruptif pada anak dapat disebabkan oleh faktor internal maupun eksternal. Faktor internal dapat disebabkan oleh kepribadian/temperamen maupun kognitif anak yang diturunkan dari orang tuanya. Sementara, faktor eksternal dapat berasal dari kondisi lingkungan dan pola asuh orang tua.

Pola asuh orang tua memegang peranan besar dalam memunculkan sikap disruptif pada anak.
Pola asuh yang tidak tepat ini sering disebut sebagai stess pengasuhan, yaitu suatu kondisi dimana orang tua merasa tidak mampu memenuhi peran sebagai orang tua dan kondisi tersebut kerap menyebabkan tekanan psikologi pada orang tua yang berimbas pada cara orang tua dalam mengasuh anak mereka. Cooper, McLanahan, Meadows, dan Brooke-Guns (2009).

\section{Authoritative Parenting untuk Mereduksi Perilaku Disruptif Anak}

Salah satu cara yang dapat digunakan dalam pola asuh otoritatif dalam mereduksi perilaku disruptif anak adalah melalui "inductive discipline," dimana anak didorong untuk mempunyai sikap empati, menolong, berhati-hati, dan baik terhadap orang lain (Krevans and Gibbs 1996; Knafo and Plomin 2006). Dalam prakteknya, inductive discipline ini dapat dilakukan melalui aktivitasaktivitas berikut; 1) Shaping behavior through reasoning, dimana orang tua berbicara dengan anak alasan-alasan dibalik adanya peraturan. 2) Emotion coaching, dimana orang tua mengajarkan kepada anak bagaimana strategi coping yang harus dilakukan ketika anak merasa marah, sedih, atau takut. 3) Emphasizing empathy and concern for others, dimana orang tua mengajarkan kepada anak tentang konsekuensi dari perilaku dia terhadap orang lain.

Beberapa penelitian menunjukan bahwa perasaan empati dan ingin menolong telah muncul pada anak bahkan diawal-awal usianya, yang perlu dilakukan orang tua adalah mengembangkan keterampilan moral reasoning dengan cara mendiskusikannya dengan anak bagaimana perilaku dia akan berakibat pada orang lain. Penelitian yang dilakukan oleh Bednar and Fisher (2003) menunjukan bahwa siswa yang diasuh secara otoritatif oleh orang tuanya senderung mengatakan bahwa orang tua mereka mempunyai pengaruh terhadap cara dia menyelesaikan masalah.

\section{METODOLOGI PENGABDIAN}

Pelaksanaan pengabdian kepada masyarakat ini menggunakan tiga metode berikut:

1. Teknik Ceramah

Metode ini disampaikan kepada orangtua sebagai peserta pelatihan, tim pengabdian sebagai pemberi materi atau pelatih memberikan materi mengenai 
authoritatif parenting dan materi mengenai perilaku distruptif. Pemaparan dilaksanakan secara daring atau online melalui zoom meeting. Hal ini dilakukan karena daerah tempat mitra merupakan salah satu zona merah yang terdampak pandemi covid-19. Materi diberikan dengan cara interaktif dan menggunakan bantuan powerpoint dengan tujuan agar materi yang disampaikan dapat dipahami dan di mengerti oleh peserta pelatihan.

\section{Teknik Diskusi}

Teknik diskusi ini juga dilakukan melalui interaksi virtual dengan media Zoom Meeting. Peserta diberikan kesempatan untuk mendiskusikan mengenai masalah yang dihadapi, kendala dan solusi terkait dengan pelatihan authoritatif parenting dan perilaku distruptif yang ditunjukkan oleh anak.

\section{Teknik Pendampingan}

Teknik ini dilakukan setelah pelatihan selesai dilakukan. lanjutan Pendampingan merupakan program yang bersifat fleksibel dan mandiri. Artinya ketika orangtua membutuhkan pendampingan dari tim pengabdian maka akan diberikan pendampingan secara virtual.

\section{PELAKSANAAN KEGIATAN}

Pelaksanaan pelatihan authoritatif parenting dalam rentang waktu September 2020 s/d Oktober 2020. Kegiatan pelatihan ini terdiri dari tiga tahap, yaitu:

1. Tahap perencanaan dan Sosialisasi

Tim peneliti menentukan masalah yang ada di lapangan (SD X kota Cimahi) sebagai mitra dalam kegiatan pengabdian ini. Selanjutnya tim melakukan observasi dan wawancara kepada kepala sekolah, guru dan orang tua guna mendapatkan data awal untuk merumuskan masalah secara khusus.

2. Tahap Pelaksanaan

Tahap pelaksanaan pelatihan ini dilakukan secara daring atau secara online dikarenakan kondisi pandemic covid-19 dan pemberlakuan pembatasan social. Pelaksanaan pelatihan dilakukan dalam satu sesi pertemuan dan dilakukan pendampingan secara fleksibel melalui WhatsApp Group dan Zoom Meeting. Pelaksanaan pengabdian ini diikuti oleh seorang kepala sekolah, 4 orang guru dan 5 orang tua siswa. Tingkat Pendidikan dari orang tua siswa yaitu sebanyak 3 orang yaitu lulusan SMA dan sebanyak 2 orang lulusan SMP.

\section{Tahap Evaluasi}

Pada tahap ini dilakukan evaluasi dari hasil pengabdian dengan menggunakan observasi dan angket. Angket yang digunakan merupakan alat pengumpulan data mengenai perilaku distruptif pada anak sebelum dan setelah diberikan pelatihan authoritatif parenting.

Tabel 1. Tabel Tahapan Pelaksanaan Pelatihan

\begin{tabular}{|c|c|c|}
\hline No & $\begin{array}{l}\text { Tahapan } \\
\text { Kegiatan }\end{array}$ & Keterangan \\
\hline 1 & $\begin{array}{l}\text { Perencanaan } \\
\quad \text { dan } \\
\text { Sosialisasi }\end{array}$ & $\begin{array}{l}\text { Merumuskan } \\
\text { masalah, membuat } \\
\text { penjadwalan dan } \\
\text { melakukan } \\
\text { sosialisasi secara } \\
\text { daring }\end{array}$ \\
\hline 2 & $\begin{array}{c}\text { Pelaksanaan } \\
\text { Pelatihan }\end{array}$ & $\begin{array}{l}\text { Melaksanakan } \\
\text { pelatihan secara } \\
\text { daring }\end{array}$ \\
\hline 3 & $\begin{array}{c}\text { Pelaksanaan } \\
\text { Evaluasi }\end{array}$ & $\begin{array}{l}\text { Melakukan evaluasi } \\
\text { dengan } \\
\text { menggunakan alat } \\
\text { bantu angket } \\
\text { mengenai } \\
\text { authoritatif } \\
\text { parenting dan } \\
\text { perilaku distruptif }\end{array}$ \\
\hline
\end{tabular}

\section{HASIL DAN PEMBAHASAN}

Pelaksanaan pelatihan ini berjalan dengan lancar dan baik. Pelatihan terselenggara sesuai dengan rencana yang sudah dibuat yaitu pelatihan dilakukan secara daring atau online melalui zoom meeting. 


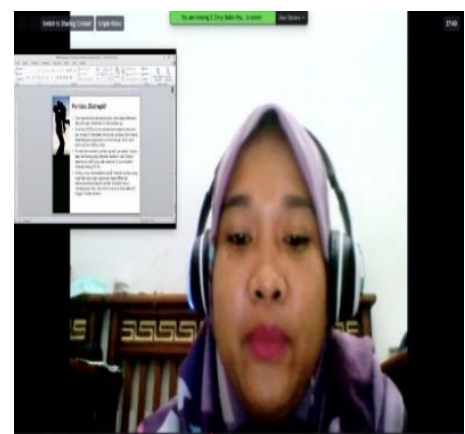

Gambar 1. Pemaparan Materi Tentang authoritative parenting dan perilaku distruptif

Pada sesi 1 ini merupakan pemaparan dari tim pengabdian mengenai authoritative parenting. Pemaparan ini dilakukan dengan menggunakan media zoom meeting dan pemateri menampilkan materi dengan menggunakan power point. Orang tua cukup antusias dengan materi yang disampaikan. Hal ini terlihat dari banyaknya pertanyaan yang diajukan oleh orang tua terkait dengan authoritative parenting. Pertanyaan yang diajukan oleh orang tua menunjukkan bahwa respon dari orang tua terhadap pelatihan sangat baik.

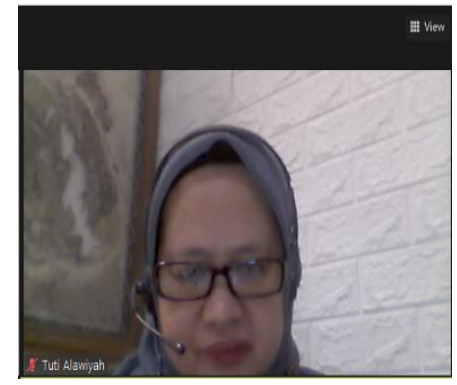

Gambar 2. Pemaparan Materi Tentang Perilaku Distruptif Anak

Pada sesi ke 2 tim pengabdi memberikan materi mengenai perilaku distruptif anak. Orang tua terlihat antusias dengan materi yang diberikan, hal ini terlihat dari banyak orang tua yang bertanya mengenai perilaku yang ditunjukkan oleh anaknya. Orang tua merasa antusias karena mendapatkan informasi baru. Keterbatasan pengetahuan karena pengaruh Pendidikan orang tua, membuat orang tua banyak yang tidak mengetahui mengenai perilaku distruptif yang ditunjukkan oleh anak. Pada sesi ke dua ini juga lebih banyak orang tua yg mendiskusikan dan berbagi cerita mengenai perilaku anak di rumah dan di sekolah serta bagaimana cara yang dilakukan oleh orang tua. Orang tua terlihat insight sesuatu setelah materi disampaikan. Respon dari orang tua sangat baik ketika materi perilaku distruptif diberikan.

Tabel 2. Respon angket Pelatihan authoritative parenting

\begin{tabular}{|c|c|c|c|c|}
\hline \multirow[t]{2}{*}{ Pernyataan } & \multicolumn{2}{|c|}{$\begin{array}{l}\text { Sebelum } \\
\text { Pelatihan }\end{array}$} & \multicolumn{2}{|c|}{$\begin{array}{l}\text { Sesudah } \\
\text { Pelatihan }\end{array}$} \\
\hline & $\begin{array}{l}\mathrm{Ya} \\
(\%)\end{array}$ & $\begin{array}{c}\text { Tidak } \\
(\%)\end{array}$ & $\begin{array}{l}\mathrm{Ya} \\
(\%)\end{array}$ & $\begin{array}{c}\text { Tidak } \\
(\%)\end{array}$ \\
\hline $\begin{array}{l}\text { Apakah ibu } \\
\text { mengetahui Pola } \\
\text { Asuh / Parenting? }\end{array}$ & 35 & 65 & 100 & 0 \\
\hline $\begin{array}{l}\text { Apakah ibu } \\
\text { menggunakan } \\
\text { authoritative } \\
\text { parenting? }\end{array}$ & 15 & 85 & 80 & 20 \\
\hline $\begin{array}{l}\text { Apakah ibu } \\
\text { pernah mencari } \\
\text { informasi } \\
\text { mengenai } \\
\text { authoritative } \\
\text { parenting? }\end{array}$ & 30 & 70 & 80 & 20 \\
\hline $\begin{array}{l}\text { Apakah ibu } \\
\text { merasa } \\
\text { authoritative } \\
\text { parenting } \\
\text { penting? }\end{array}$ & 50 & 50 & 90 & 10 \\
\hline $\begin{array}{l}\text { Apakah ibu } \\
\text { merasa puas } \\
\text { dengan pelatihan } \\
\text { authoritative } \\
\text { parenting yang } \\
\text { diberikan? }\end{array}$ & 20 & 80 & 95 & 5 \\
\hline $\begin{array}{l}\text { Apakah ibu } \\
\text { tertarik } \\
\text { menggunakan } \\
\text { authoritative } \\
\text { parenting? }\end{array}$ & 20 & 80 & 90 & 10 \\
\hline
\end{tabular}

\begin{tabular}{lllll}
\hline $\begin{array}{l}\text { Apakah ibu merasa } \\
\text { authoritative parenting } \\
\text { membantu dalam }\end{array}$ & 30 & 70 & 85 & 15 \\
$\begin{array}{l}\text { menurunkan perilaku } \\
\text { distruptif anak? }\end{array}$ & & & & \\
\hline $\begin{array}{l}\text { Apakah materi yang } \\
\text { diberikan dapat } \\
\text { dimengerti? }\end{array}$ & 40 & 60 & 80 & 20 \\
& & & & \\
\hline
\end{tabular}

$\begin{array}{llr}\text { Rata-rata } & 30 & 87,5\end{array}$

Tabel 2. Merupakan rekap angket respon orang tua yang diberikan sebelum dan setelah diberikan pelatihan authoritative parenting. Kuesioner ini 
diberikan dalam bentuk google form. Terdapat 8 item pernyataan yang bertujuan untuk menganalisa pemahaman dan penggunaan authoritative parenting oleh orang tua. Sebelum diberikan pelatihan, pemahaman orang tua mengenai authoritative parenting hanya $30 \%$. Namun, setelah diberikan pelatihan pemahaman orang tua menjadi meningkat menjadi $87,3 \%$. Dengan kata lain, pada pelatihan authoritative parenting terjadi peningkatan pemahaman dan penggunaan authoritative parenting sebesar $57,3 \%$.

Tabel 3. Respon angket perilaku distruptif pada anak

\begin{tabular}{|c|c|c|c|c|}
\hline \multirow[t]{2}{*}{ Pernyataan } & \multicolumn{2}{|c|}{$\begin{array}{l}\text { Sebelum } \\
\text { Pelatihan }\end{array}$} & \multicolumn{2}{|c|}{$\begin{array}{c}\text { Sesudah } \\
\text { Pelatihan }\end{array}$} \\
\hline & $\begin{array}{l}\mathrm{Ya} \\
(\%)\end{array}$ & $\begin{array}{c}\text { Tidak } \\
(\%)\end{array}$ & $\begin{array}{l}\mathrm{Ya} \\
(\%)\end{array}$ & $\begin{array}{c}\text { Tidak } \\
(\%)\end{array}$ \\
\hline $\begin{array}{l}\text { Apakah ibu } \\
\text { mengetahui } \\
\text { mengenai } \\
\text { perilaku } \\
\text { distruptif? }\end{array}$ & 50 & 50 & 50 & 50 \\
\hline $\begin{array}{l}\text { Apakah anak } \\
\text { menunjukkan } \\
\text { perilaku distruptif } \\
\text { di rumah? }\end{array}$ & 85 & 15 & 30 & 70 \\
\hline $\begin{array}{l}\text { Apakah anak } \\
\text { menunjukkan } \\
\text { perilaku distruptif } \\
\text { di sekolah? }\end{array}$ & 60 & 40 & 25 & 75 \\
\hline Rata-rata & 65 & & 35 & \\
\hline
\end{tabular}

Tabel 3. Merupakan rekap angket respon orang tua sebelum dan setelah diberikan materi mengenai perilaku distruptif pada anak. Terdapat tiga item pernyataan yang menunjukkan pengetahuan orang tua mengenai perilaku distruptif yang ditunjukkan anak baik di rumah maupun di sekolah. Pengetahuan orang tua mengenai perilaku distruptif sebelum dan setelah dilaksanakan program sama-sama sebanyak $50 \%$, hal ini dipengaruhi oleh factor Pendidikan orang tua yang kurang memahami mengenai authoritative parenting. Sebelum diberikan materi, pemahaman orang tua mengenai perilaku distruptif sebanyak $65 \%$. Setelah diberikan materi mengenai perilaku distruptif, terlihat adanya penurunan perilaku distruptif pada anak baik di rumah maupun di sekolah menjadi 35\%. Dengan kata lain, pemberian materi dapat menurunkan atau mereduksi perilaku distruptif pada anak sebesar $30 \%$.

Berdasarkan observasi yang dilakukan setelah diberikan pelatihan, orang tua dapat menggunakan authoritative parenting dalam mendidik dan mendampingi anak-anak melewati tugas-tugas perkembangan. Dengan digunakannya authoritative parenting membuat perilaku distruptif yang di tunjukkan oleh anak menjadi menurun. Artinya pelatihan authoritative parenting dapat mereduksi perilaku distruptif pada anak.

\section{KESIMPULAN}

Berdasarkan hasil pelaksanaan pelatihan authoritative parenting dapat disimpulkan bahwa kegiatan pelatihan mendapatkan respon positif dan baik dari orangtua. Selama dilaksanakan pelatihan dan sesi diskusi orang tua terlihat aktif dan banyak berpendapat dengan mengajukan pertanyaan atau berbagi informasi mengenai pengalaman dalam menagtasi perilaku distruptif baik di rumah maupun di sekolah. Berdasarkan hasil angket respon orang tua yang diberikan sebelum dan setelah diberikan pelatihan authoritative parenting menunjukkan adanya peningkatan pemahaman dan penggunaan authoritative parenting sebesar 57,3\%. Sedangkan pada angket respon orang tua tua sebelum dan setelah diberikan materi mengenai perilaku distruptif pada anak menunjukkan adanya penurunan atau mereduksi perilaku distruptif pada anak sebesar $30 \%$. Hal ini dapat disimpulkan bahwa kegiatan pengabdian ini cukup baik dan efektif.

\section{DAFTAR PUSTAKA}

Asizah (2015). Children Disruptive Behavior Wellbeing: Pentingnya Hubungan Anak dan Orang Tua. Seminar psikologi \& kemanusiaan. UMM, ISBN: 978-979-796324-8. Tersedia secara online di; http://mpsi.umm.ac.id/files/file/4654\%20Asizah.pdf

Baumrind D. Prototypical descriptions of 3 parenting styles. Psychology. 1966;37.

Baumrind D. Child care practices anteceding three patterns of preschool behavior. Genetic Psychology Monographs. 1967;75(1):43-88. Bednar DE and Fisher TD. 2003. Peer referencing in adolescent decision making as a function of 
perceived parenting style. Adolescence. 38(152):607-21.

Campbell, S. B. (2006). Maladjustment in preschool children: A developmental psychopathology perspective. In K. McCartney \& D. Phillips (Eds.), Blackwell handbook of early childhood development (pp. 358 - 377). Oxford, OX: Blackwell Publishing.

Crozeir, S. \& Tincani, M. J. (2005). Using a modified social story to decrease disruptive behavior of a child with autism. Focus on Autism And Other Developmental Disabilities, 20 (3), 150-157.

Cooper, C. E., McLanahan, S. S., Meadows, S. O., \& Brooks-Gunn, J. (2009). Family structure transitions and maternal parenting stress. Journal of Marriage and Family, 71 (3), 558-574.

Gardner, F., \& Shaw, D. S. (2008). Behavioural problems of infancy and pre-school children. In M. Rutter, D. Bishop, D. Pine, S. Scott, J. Stevenson, E. Taylor, \& A. Thapar (Eds.), Rutter's child and adolescent psychiatry, 5th edition (pp. 882-894). London: Blackwell Press.

Gwen Dewar (2017). The authoritative parenting style. An evidence-based guide. Tersedia secara online di: https://www.parentingscience.com/authorita tive-parenting-style.html.

Krevans J and Gibbs JC. 1996. Parents' use of inductive discipline: relations to children's empathy and prosocial behavior. Child Development, 67: 3263-77.

Knafo A and Plomin R. 2008. Prosocial behavior from early to middle childhood: genetic and environmental influences on stability and change. Developmental psychology 42(5):771-86.

Maccoby EE and Martin JA. 1983. Socialization in the context of the family: Parent-child interaction. In P. H. Mussen (ed) and E. M. Hetherington (vol. ed.), Handbook of child psychology: Vol. 4. Socialization, personality, and social development (4th ed., pp. 1-101). New York: Wiley.
Novitasari (2016). Kecenderungan Perilaku Disruptif pada Anak Usia Prasekolah Ditinjau dari Stres Pengasuhan Ibu. Jurnal Ilmiah Psikologi. http://journal.unnes.ac.id/nju/index.php.

Schroeder, C. S., \& Gordon, B. N. (2002). Depression. In C. S. Schroeder \& B. N. Gordon, Assessment and treatment of childhood problems (2nd ed., pp. 377-416). New York: Guilford. 